Int. J. Electrochem. Sci., 14 (2019) 9633 - 9646

\title{
Acceleration Effects of Hydroxylamine Sulfate on Electroless Gold Plating on Ni-Pd Surfaces
}

\author{
Wenjuan Yao, Daoxin $\mathrm{Wu}^{*}$, Zhongliang Xiao, Yiwei Wang, Ronghua Yang \\ School of Chemistry and Food Engineering, Changsha University of Science and Technology, \\ Changsha, 410114, China \\ *E-mail: daoxinwu@126.com
}

doi: $10.20964 / 2019.10 .05$

Received: 9 June 2019 / Accepted: 24 July 2019 / Published: 30 August 2019

\begin{abstract}
Hydroxylamine sulfate (HAS) was used to accelerate $\mathrm{Au}$ deposition following the covering of a Ni-Pd substrate with Au layer. The influence of HAS on the electroless gold plating bath and deposition procedure was investigated. The acceleration mechanism, nucleation mechanism, and corrosion resistance were analyzed via electrochemical methods. The surface microtopography and the chemical and phase compositions of Au layers were also characterized. Results showed that HAS did not affect the stability of the plating bath because of the reaction of cyanide and hydroxylamine. HAS also positively accelerated Au deposition due to its excellent catalyzed oxidation on the Au surface. As the optimum concentration, $0.02 \mathrm{M} \mathrm{HAS}$ increased the deposition rate by $70 \%$. At the same deposition time, the transformation of the nucleation model increased the size of Au grains and smoothened the surface of the Au layer after the addition of 0.02 M HAS.
\end{abstract}

Keywords: electroless gold plating, electrochemical methods, HAS, nucleation mechanism

\section{FULL TEXT}

(C) 2019 The Authors. Published by ESG (www.electrochemsci.org). This article is an open access article distributed under the terms and conditions of the Creative Commons Attribution license (http://creativecommons.org/licenses/by/4.0/). 